\title{
Сорбционное концентрирование $\alpha$-аминокислот сополимерами 1-винил-3,5-диметилпиразола с этиленгликольдиметакрилатом
}

\author{
Лавлинская М.С., Кузнецов В.А., Хохлов В.Ю., Шаталов Г.В. \\ ФГБОУ ВО «Воронежский государственный университет», Воронеж
}

Поступила в редакцию 16.12.2016 г.

\begin{abstract}
Изучены сорбционные свойства новых сетчатых сополимеров на основе 1-винил-3,5диметилпиразола и этиленгликольдиметакрилата по отношения к $\alpha$-аминокислотам - гистидину и триптофану - в статических и динамических условиях при различных значениях $\mathrm{pH}$. Установлено, что предложенные сорбенты характеризуются высокими значениями степеней концентрирования, малым временем извлечения по отношению к аминокислотам, что позволяет использовать их для сорбционного концентрирования гистидина и триптофана. На основании проведенных исследований разработана методика сорбционно-спектрофотометрического определения гистидина и триптофана в водных растворах.
\end{abstract}

Ключевые слова: сорбционное концентрирование, $\alpha$-аминокислоты, полимерные сорбенты, спектрофотометрия.

\section{Preconcentration of $\alpha$-amino acids by 1-vinyl-3,5-dimethylpyrazole and ethylene dimethacrylate copolymers}

\author{
Lavlinskaya M.S., Kuznetsov V.A., Khokhlov V.Yu., Shatalov G.V. \\ Voronezh State University, Voronezh
}

The goal of present work is establishing sorption concentrating characteristics of essential $\alpha$-amino acids tryptophan and histidine by new copolymers based on 1-vinyl-3,5-dimethylpyrazole (VDMP) with ethylene dimethacrylate (EDMA). Cross-linked copolymers of VDMP and EDMA with different degree of cross-linking are synthesized by free radical copolymerization in chloroform and methanol. It's found that sorption characteristics of both amino acids are higher for copolymers obtaining in chloroform, and the best sorption characteristics are achieved for copolymers with VDMP:EDMA=1:15 molar ratio in static sorption with spectrophometric determination. VDMP:EDMA=1:15 copolymer synthesized in chloroform also demonstrates the highest values of distribution coefficient in case of dynamic sorption. Researching of $\mathrm{pH}$ effect shows that sorption efficiency is maximal in acid media. Amino acid desorption by water is not quantitative, but $0.1 \mathrm{M} \mathrm{NaOH}$ using allows reaching quantitative desorption. Based on carried out researching the technique of sorption-spectrophotometric determination of histidine and tryptophan in aqueous solutions is proposed. To sum up new copolymers based on VDMP and EDMA are effective sorbents for histidine and tryptophan from aqueous media in static and dynamic sorption.

Keywords: sorption concentration, $\alpha$-amino acids, polymeric sorbents, spectrophotometry 


\section{Введение}

Концентрирование неорганических и органических веществ широко используют для решения технологических и аналитических задач [1-3]. Необходимость проведения концентрирования может быть связана с недостаточной чувствительностью метода прямого определения вещества, его неравномерного распределения в анализируемой пробе, препаративных и др. целях. Наиболее перспективным является сорбционное концентрирование, которое позволяет получать высокие коэффициенты концентрирования и исключать применение токсичных растворителей.

В качестве сорбентов для концентрирования многочисленных органических соединений наиболее часто применяют полимеры, различающиеся структурой и составом, в частности, сополимеры стирола и метилметакрилата с дивинилбензолом [1,4-7], полиуретаны $[1,8]$, ковалентно и нековалентно модифицированные органическими соединениями кремнеземы $[1,2,4,9,10]$, импринтированные полимеры $[11,12]$ и др.

Наиболее перспективным с целью сорбционного концентрирования органических веществ представляется использование полимеров $N$-виниламидного ряда, нашедших широкое применение в аналитической практике [13], в особенности сополимеров $N$-винилпирролидона и $N$-винилкапролактама с этиленгликольдиметакрилатом, которые обладают высокой комплексообразующей способностью и низкой токсичностью. Такие полимеры показали себя как эффективные сорбенты для выделения и концентрирования нитрофенолов [14,15].

Известны работы, в которых данные полимеры использовались для концентрирования биологически активных веществ, в частности, витаминов и аминокислот [16]. Однако представляет интерес создание новых сополимеров с большей емкостью, лучшими параметрами концентрирования, что позволит им найти широкое применение в аналитической практике.

Для синтеза полимерных сорбентов на основе новых функциональных мономеров (ФМ) перспективными являются представители ряда $\mathrm{N}$-винильных азолов, обладающие хорошей комплексообразующей способностью и характеризующиеся широким комплексом ценных свойств, такими как низкая токсичность, способность к кислотно-основному взаимодействию, координированию органических и неорганических соединений [17]. В качестве сшивающего агента (СА) интерес представляют диметакрилаты гликолей, содержащие полярные $>\mathrm{C}=\mathrm{O}$-группы. Благодаря сочетанию в структуре полимера таких мономерных звеньев становится возможным взаимодействие между $\alpha$-аминокислотами и сорбентом с образованием межмолекулярных Н-связей и других типов взаимодействий, способствующих сорбции [18].

Применение аминокислот в качестве объектов концентрирования связано с тем, что они входят в состав многочисленных лекарственных препаратов и биологически активных веществ, поэтому осуществление их сорбционного концентрирования для последующего определения аминокислот как целевых компонентов, либо их удаление из анализируемых сред для последующего определения белков является важной аналитической задачей [19]. Решение данной задачи проводят с применением различных полимеров, в частности, поли- $N$-виниламидов и поли- $N$-винилазолов $[20,21]$. Однако работы по применению в сорбционном концентрировании аминокислот новыми сополимерами на основе $\mathrm{N}$-винилазолов с пиразольными циклами и этиленгликольдиметакрилатом отсутствуют, хотя, можно ожидать, что сорбенты на их основе будут обладать лучшими характеристиками (меньшее время извлечения, большая степень концентрирования) [22]. Поэтому, цель работы - установление особенностей сорбционного концентрирования $\alpha$-аминокислот гистидина и триптофана 
новыми сополимерами на основе 1-винил-3,5-диметилпиразола (ВДМП) с этиленгликольдиметакрилатом (ЭГДМА).

\section{Эксперимент}

В качестве адсорбтивов использовали товарные $\alpha$-аминокислоты гистидин (His) и триптофан (Trp) марки «ХЧ», без дополнительной очистки. Рабочие растворы готовили растворением точных навесок в дистиллированной воде непосредственно перед использованием.

Для определения полной обменной емкости $E$ сорбентов $1.0000 \pm 0.0002$ г испытуемого сухого сополимера заливали $200 \mathrm{~cm}^{3}$ раствора $0.1 \mathrm{M} \mathrm{HCl}$ и выдерживали в течение 24 ч, после чего отбирали аликвоты по $25 \mathrm{~cm}^{3}$ и титровали $0.1 \mathrm{M}$ водным раствором $\mathrm{NaOH}$ в присутствии метилоранжа.

Полную обменную емкость $E$ рассчитывали по формуле [23]:

$$
E=\frac{200-8 V_{1}}{10 g},
$$

где $V_{l}$ - объем $0.1 \mathrm{M} \mathrm{NaOH}$, пошедший на титрование, $\mathrm{cm}^{3} g$ - масса сорбента, г.

Сорбцию аминокислот в статических условиях проводили по следующей методике. В термостатируемый сосуд для экстракции помещали $0.0500 \pm 0.0002$ г сополимера и добавляли $5 \mathrm{~cm}^{3}$ водного раствора аминокислоты. Концентрация для каждого сополимера была индивидуальна и варьировалась в интервале 0.0100.036 моль/дм ${ }^{3}$. Смесь встряхивали на вибросмесителе до установления равновесия в течение 30 минут, сорбент отделяли от раствора центрифугированием в течение 15 минут при 1500 об/мин. Концентрацию аминокислоты определяли спектрофотометрически по заранее определенным спектральным максимумам $\lambda_{\max }=211$ нм для гистидина и 279 нм для триптофана с использованием градуировочного графика. Ошибка определения составила $3 \%$. Степени извлечения и коэффициенты распределения аминокислоты рассчитывали согласно уравнениям [15]:

$$
R=\frac{C o-C}{C o} \times 100, D=\frac{R V}{(100-R) m},
$$

где $C_{0}$ и $C$ - концентрации гистидина до и после экстракции, моль/дм ${ }^{3}, V-$ объем анализируемой пробы, $\mathrm{cm}^{3}, m$ - масса сорбента, г.

Коэффициент концентрирования в статических условиях определяли как отношение [15]:

$$
K=\frac{m_{g}}{m_{o}},
$$

где $m_{6}$ и $m_{o}$ - масса водной и полимерной фазы соответственно после сорбции, г.

Для изучения сорбции аминокислот в динамических условиях через стеклянную колонку диаметром $0.5 \mathrm{~cm}$, заполненную $3.0000 \pm 0.0002$ г сополимера (высота слоя - $15.00 \pm 0.01 \mathrm{~cm})$, пропускали с помощью перистальтического насоса растворы известных концентраций, находящихся в интервале 0.020-0.072 моль/дм³; $\mathrm{pH}$ $=5.5 \pm 0.2$, со скоростью $5 \mathrm{~cm}^{3} /$ мин. Для контроля сорбции отбирали порции жидкой фазы на выходе из колонки. Концентрацию аминокислот определяли спектрофотометрически. Строили выходные кривые удерживания в виде зависимостей $C / C_{0}$ от $V$, где $C$ и $C_{0}$ - концентрации аминокислот на выходе и на входе из колонки соответственно, моль/дм ${ }^{3} ; V-$ общий объем раствора, пропущенного через колонку, $\mathrm{cm}^{3}$.

С помощью полученных кривых определяли объем проскока $V_{B}$ - объем выходной фазы, при котором концентрация аминокислот начинает значимо отличаться от нуля, см ${ }^{3}$; объемом удерживания $V_{R}$ - объем выходной фазы, при котором выполняется равенство $C=C_{0} / 2, \mathrm{~cm}^{3}$. 
Для определения влияния величины $\mathrm{pH}$ на сорбционные характеристики эксперимент повторяли в тех же условиях, используя растворы аминокислот с $\mathrm{pH}$

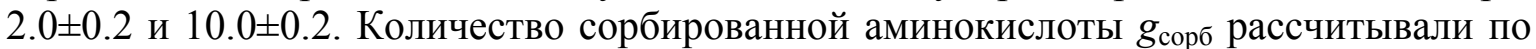
формуле [23]:

$$
g_{\text {сорб }}=\left(C_{o}-\Sigma C_{i} V_{o}\right) V,
$$

где $C_{i}$ - концентрация аминокислоты в отбираемой пробе, моль/дм ${ }^{3} ; V_{0}$ - объем отбираемой пробы, см³

Эффективность сорбции X определяли как отношение [23]:

$$
X=\frac{g_{\text {сор } \tilde{}}}{E} \cdot 100 \cdot
$$

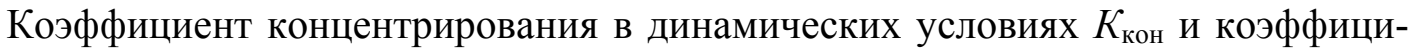
ент распределения $K_{S L(G)}$ рассчитывали по уравнениям [23]:

$$
K_{K O H}=\frac{V_{B}}{V_{S}} ; K_{S L(G)}=\frac{V_{R}}{V_{S}},
$$

где $V_{B}$ - объем проскока, $\mathrm{cm}^{3}, V_{S}$ - объем сорбента в колонке, $\mathrm{cm}^{3}, V_{R}$ - объем удерживания, $\mathrm{cm}^{3}$.

Для десорбции аминокислот из колонок применяли дистиллированную воду и $0.1 \mathrm{M}$ водный раствор $\mathrm{NaOH}$. Строили кривые десорбции - зависимости концентрации аминокислот на выходе из колонки от объема элюента, пропущенного через колонку.

\section{Обсуждение результатов}

Сорбционные характеристики полимеров зависят от условий их получения, в частности, от природы растворителя, использованного при синтезе. Известно [15], что лучшими сорбционными характеристиками обладают сополимеры, полученные в хлороформе и метаноле. Как видно из табл.1, сорбенты, синтезированные в хлороформе, демонстрируют более высокие значения $E, R$ и $D$ по отношению к аминокислотам. Это обусловлено высокой склонностью хлороформа к порообразованию в процессе синтезе, что приводит к получению более пористых сорбентов по сравнению с другими растворителями [14].

\begin{tabular}{|c|c|c|c|c|c|c|c|c|}
\hline \multirow{2}{*}{ Сорбент } & \multirow{2}{*}{ Растворитель } & \multirow{2}{*}{$\begin{array}{c}E, \\
\text { ммоль }\end{array}$} & \multicolumn{3}{|c|}{ His } & \multicolumn{3}{|c|}{ Trp } \\
\hline & & & $D$ & $R, \%$ & $K$ & $D$ & $R, \%$ & $K$ \\
\hline $\begin{array}{c}\text { ВДМП- } \\
\text { ЭГДМА=1:1 }\end{array}$ & \multirow{4}{*}{$\mathrm{CHCl}_{3}$} & 6.31 & $400 \pm 25$ & 80 & $110 \pm 4$ & $257 \pm 26$ & 75 & $108 \pm 3$ \\
\hline $\begin{array}{c}\text { ВДМП- } \\
\text { ЭГДМА =1:15 }\end{array}$ & & 8.04 & $1011 \pm 37$ & 91 & $131 \pm 5$ & $809 \pm 39$ & 89 & $124 \pm 8$ \\
\hline $\begin{array}{c}\text { ВДМП- } \\
\text { ЭГДМА=1:30 }\end{array}$ & & 14.59 & $669 \pm 28$ & 87 & $118 \pm 3$ & $426 \pm 21$ & 81 & $113 \pm 5$ \\
\hline $\begin{array}{c}\text { ВДМП- } \\
\text { ЭГДМА=1:60 }\end{array}$ & & 18.11 & $376 \pm 18$ & 79 & $109 \pm 2$ & $300 \pm 16$ & 72 & $105 \pm 6$ \\
\hline $\begin{array}{c}\text { ВДМП- } \\
\text { ЭГДМА=1:1 }\end{array}$ & \multirow{4}{*}{$\mathrm{CH}_{3} \mathrm{OH}$} & 4.94 & $245 \pm 10$ & 71 & $104 \pm 3$ & $223 \pm 14$ & 69 & $103 \pm 4$ \\
\hline $\begin{array}{c}\text { ВДМП- } \\
\text { ЭГДМА=1:15 }\end{array}$ & & 6.27 & $567 \pm 14$ & 85 & $117 \pm 5$ & $426 \pm 23$ & 81 & $110 \pm 6$ \\
\hline $\begin{array}{c}\text { ВДМП- } \\
\text { ЭГДМА=1:30 }\end{array}$ & & 11.79 & $488 \pm 15$ & 83 & $115 \pm 2$ & $300 \pm 19$ & 75 & $107 \pm 3$ \\
\hline $\begin{array}{c}\text { ВДМП- } \\
\text { ЭГДМА=1:60 }\end{array}$ & & 15.36 & $203 \pm 11$ & 67 & $102 \pm 1$ & $178 \pm 15$ & 64 & $101 \pm 2$ \\
\hline
\end{tabular}

Таблица 1. Сорбция $\alpha$-аминокислот в статических условиях $(\mathrm{pH}=5.5 \pm 0.2$; время сорбции 30 мин; $n=4 ; P=0.95 ; V=5 \mathrm{~cm}^{3} ; m=0.0500 \pm 0.0002$ г) 
Степень сшивки сополимера так же оказывает значительное влияние на сорбционные характеристики. Несмотря на то, что сорбенты с соотношением $\Phi \mathrm{M}: \mathrm{CA}=1: 60$ обладают большей сорбционной емкостью $E$, сополимеры с соотношением ФМ:CA=1:15 и 1:30 показали более высокие значения коэффициентов распределения $D$ и степеней извлечения $R$ (табл. 1). Это обуславливается меньшим влиянием стерических затруднений в менее сшитом полимере. Однако применение очень редко сшитых сополимеров в сорбционном концентрировании затруднено из-за механической неустойчивости таких образцов.

Аналитические возможности сорбции в динамических условиях оценивали по выходным кривым сорбции. Выходные кривые, представленные на рис. 1 и 2, имеют схожий вид кривых с насыщением. Анализ полученных данных показал, что наиболее эффективными по отношению к обеим сорбируемым аминокислотам является сорбент ВДМП-ЭГДМА=1:15, полученный в хлороформе и характеризующийся коэффициентами распределения $\mathrm{K}_{\mathrm{SL}(\mathrm{G})}$, равными 52 в случае гистидина и 50 для триптофана (табл. 2 , рис. 1 и 2).

Таблица 2. Сорбция $\alpha$-аминокислот в динамических условиях (диаметр колонки 0.5 см; высота слоя сорбента $15.00 \pm 0.01 \mathrm{~cm} ; m=3.0000 \pm 0.002$ г; $W=5 \mathrm{~cm}^{3} / \mathrm{MиH} ; \mathrm{pH}=5.5 \pm 0.2$ )

\begin{tabular}{|c|c|c|c|c|c|c|c|c|c|c|c|c|}
\hline \multirow[t]{2}{*}{ Раст } & оритель & \multirow[b]{2}{*}{$\begin{array}{c}E, \\
\text { ммоль }\end{array}$} & \multicolumn{5}{|c|}{ His } & \multicolumn{5}{|c|}{ Trp } \\
\hline & Сополимер & & $\begin{array}{l}\mathrm{V}_{\mathrm{R}}, \\
\text { Мл }\end{array}$ & $\begin{array}{l}g_{\text {сорб, }} \\
\text { ммОЛЬ }\end{array}$ & $\begin{array}{l}\mathrm{X}, \\
\%\end{array}$ & $\mathrm{~K}_{\text {кон }}$ & $\mathrm{K}_{\mathrm{SL}(\mathrm{G})}$ & $\begin{array}{l}\mathrm{V}_{\mathrm{R}}, \\
\text { MЛ }\end{array}$ & $\begin{array}{l}g_{\text {сорб, }} \\
\text { ммОЛЬ }\end{array}$ & $\begin{array}{l}\mathrm{X} \\
\%\end{array}$ & $\mathrm{~K}_{\text {кон }}$ & $\mathrm{K}_{\mathrm{SL}(\mathrm{G})}$ \\
\hline \multirow{4}{*}{ 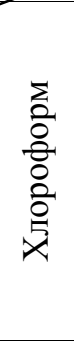 } & $\begin{array}{c}\text { ВДМП- } \\
\text { ЭГДМА=1:1 }\end{array}$ & 6.31 & 148 & 5.15 & 81 & \multirow{8}{*}{$25 \pm 2$} & 50 & 148 & 5.15 & 81 & \multirow{8}{*}{$25 \pm 1$} & 50 \\
\hline & $\begin{array}{c}\text { ВДМП- } \\
\text { ЭГДМА }=1: 15\end{array}$ & 8.04 & 155 & 7.47 & 93 & & 52 & 152 & 7.14 & 88 & & 51 \\
\hline & $\begin{array}{c}\text { ВДМП- } \\
\text { ЭГДМА=1:30 }\end{array}$ & 14.59 & 153 & 12.17 & 83 & & 52 & 147 & 11.67 & 80 & & 50 \\
\hline & $\begin{array}{c}\text { ВДМП- } \\
\text { ЭГДМА=1:60 }\end{array}$ & 18.11 & 147 & 12.43 & 69 & & 50 & 146 & 12.16 & 67 & & 49 \\
\hline \multirow{4}{*}{ 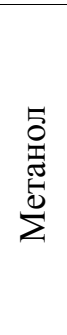 } & $\begin{array}{c}\text { ВДМП- } \\
\text { ЭГДМА=1:1 }\end{array}$ & 4.94 & 144 & 3.85 & 78 & & 49 & 143 & 3.41 & 69 & & 48 \\
\hline & $\begin{array}{c}\text { ВДМП- } \\
\text { ЭГДМА=1:15 }\end{array}$ & 6.27 & 149 & 5.14 & 82 & & 51 & 146 & 4.95 & 79 & & 50 \\
\hline & $\begin{array}{c}\text { ВДМП- } \\
\text { ЭГДМА=1:30 }\end{array}$ & 11.79 & 145 & 9.31 & 79 & & 49 & 143 & 8.59 & 73 & & 49 \\
\hline & $\begin{array}{c}\text { ВДМП- } \\
\text { ЭГДМА=1:60 }\end{array}$ & 15.36 & 144 & 10.45 & 68 & & 49 & 141 & 9.72 & 64 & & 48 \\
\hline
\end{tabular}

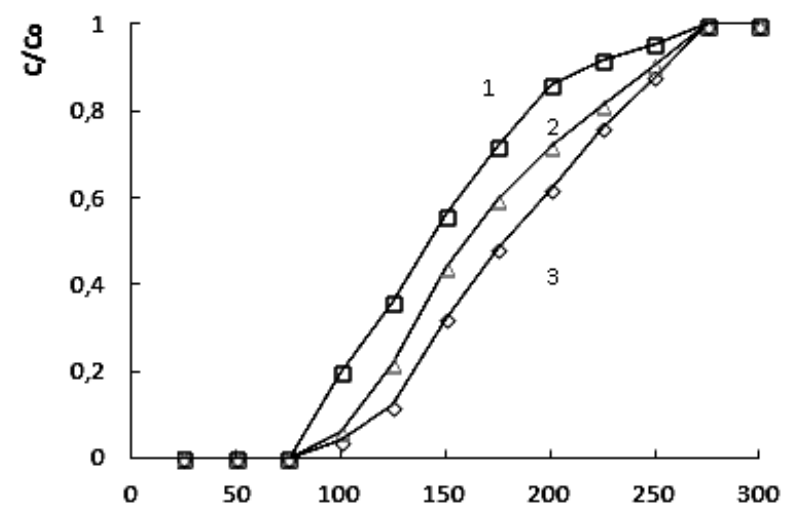

$\mathrm{V}, \mathrm{cm}^{3}$

Рис. 1. Выходные кривые сорбции гистидина при различных значения $\mathrm{pH}$ сорбентом ВДМП-ЭГДМА=1:15, синтезированном в хлороформе:

$1-\mathrm{pH}=10 ; 2-\mathrm{pH}=5.5 ; 3-\mathrm{pH}=2$. 


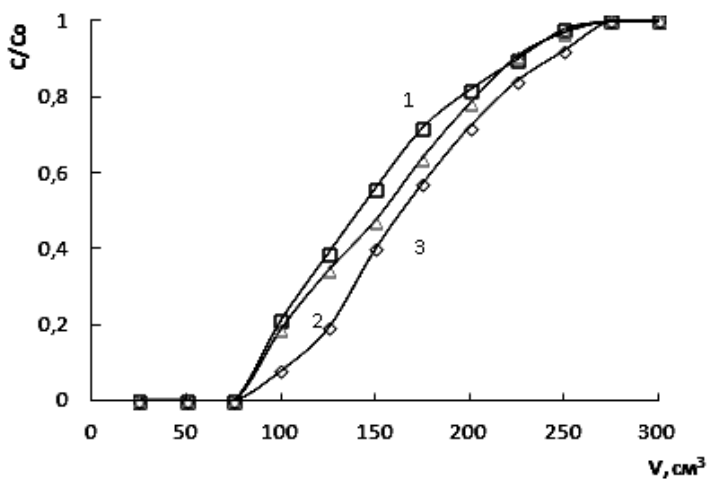

Рис. 2. Выходные кривые сорбции триптофана при различных значения $\mathrm{pH}$ сорбентом ВДМП-ЭГДМА=1:15, синтезированном в хлороформе:

$$
1-\mathrm{pH}=10 ; 2-\mathrm{pH}=5.5 ; 3-\mathrm{pH}=2 \text {. }
$$

На рис. 1 и 2 представлены кривые сорбции гистидина (1) и триптофана (2) при различных рН сорбентом ВДМП-ЭГДМА=1:15, синтезированного в хлороформе. Как видно из представленных данных, наилучшее концентрирование достигается при $\mathrm{pH}<7$ (табл. 3). Это связано с тем, что в кислой среде происходит протонирование «пиридиновых» атомов азота пиразольного цикла и атомов кислорода карбонильных групп сложноэфирных фрагментов сшивающего агента ЭГДМА [24], что способствует ионообменной сорбции с параллельно протекающим нековалентным связыванием [1]. В щелочной же среде аминокислота существует в аци-форме и сорбция обусловлена только за счет взаимодействий $\pi$-ненасыщенных фрагментов аминокислот и атомами кислорода на поверхности адсорбента [1].

Возможность осуществления количественной десорбции так же является одной из важнейших характеристик сорбента. Для осуществления десорбции через колонки, насыщенные сорбатом, пропускали дистиллированную воду. Наиболее полно десорбция протекала на сорбентах, синтезированных в метаноле, однако степень десорбции оказалась малой, порядка $30 \%$. Для достижения количественного вымывания аминокислот в качестве элюента использован $0.1 \mathrm{M}$ водный раствор $\mathrm{NaOH}$. B щелочной среде аминокислоты приобретают отрицательный и заряд и эффективно десорбируются. Наиболее полная десорбция происходит в случае сорбентов с соотношением ФМ:СА=1:1, полученных в метаноле. На рис.3 и 4 представлены кривые десорбции аминокислот водным раствором щелочи. Данные, представленные на рисунках, показывают, что наиболее эффективная десорбция наблюдается для гистидина при использовании сорбента ВДМП-ЭГДМА=1:1, синтезированного в метаноле, а триптофан десорбируется практически одинаково из всех изучаемых образцов.

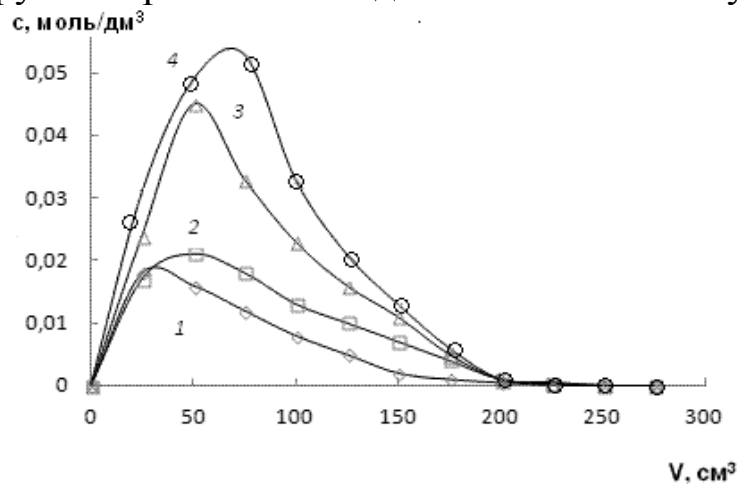

Рис. 3. Десорбция гистидина $0.1 \mathrm{M} \mathrm{NaOH}$ из сорбентов, синтезированных в хлороформе: 1 - ВДМП-ЭГДМА=1:1; 2 - ВДМП-ЭГДМА=1:15; 3 - ВДМП-ЭГДМА=1:30; 4 - ВДМП -ЭГДМА=1:60. 


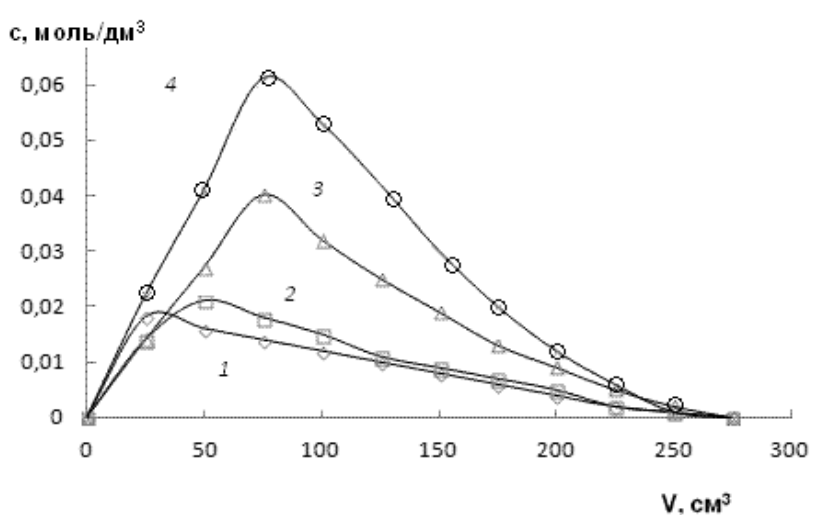

Рис. 4. Десорбция триптофана $0.1 \mathrm{M} \mathrm{NaOH}$ из сорбентов, синтезированных в метаноле: 1 - ВДМП-ЭГДМА=1:1; 2 - ВДМП-ЭГДМА=1:15; 3 - ВДМП-ЭГДМА=1:30; 4 - ВДМП-ЭГДМА=1:60.

Таблица 3. Сорбция $\alpha$-аминокислот в динамических условиях при различных величинах $\mathrm{pH}$ (диаметр колонки $0.5 \mathrm{~cm}$; высота слоя сорбента $15.00 \pm 0.01 \mathrm{~cm}$; $m=3.0000 \pm 0.0002 \Gamma ; W=5 \mathrm{~cm}^{3} /$ мин $)$

\begin{tabular}{|c|c|c|c|c|c|c|c|c|c|c|c|c|}
\hline \multirow[b]{2}{*}{ Сополимер } & \multirow[b]{2}{*}{$\begin{array}{c}E, \\
\text { ммоль }\end{array}$} & \multirow[b]{2}{*}{$\mathrm{pH}$} & \multicolumn{5}{|c|}{ His } & \multicolumn{5}{|c|}{ Trp } \\
\hline & & & $\begin{array}{l}\mathrm{V}_{\mathrm{R}}, \\
\text { мЛ }\end{array}$ & $\begin{array}{c}g \text { сорб, } \\
\text { мМоль }\end{array}$ & $\begin{array}{l}X, \\
\%\end{array}$ & $\mathrm{~K}_{\text {кон }}$ & $\mathrm{K}_{\mathrm{SL}(\mathrm{G})}$ & $\begin{array}{l}\mathrm{V}_{\mathrm{R}}, \\
\text { Мл }\end{array}$ & $\begin{array}{c}g_{\text {сорб, }} \\
\text { ммоль }\end{array}$ & $\begin{array}{l}\mathrm{X}, \\
\%\end{array}$ & $\mathrm{~K}_{\text {кон }}$ & $\mathrm{K}_{\mathrm{SL}(\mathrm{G})}$ \\
\hline ВДМП- & & 2 & 181 & 7.87 & 98 & & 62 & 168 & 7.38 & 92 & & 57 \\
\hline $\begin{array}{c}\text { ЭГДМА } \\
=1: 15, \\
\text { хлороформ }\end{array}$ & 8.04 & 10 & 143 & 5.13 & 64 & $25 \pm 2$ & 48 & 139 & 4.89 & 61 & $\begin{array}{l}25 \\
\pm 1\end{array}$ & 47 \\
\hline
\end{tabular}

На основании проведенных исследований разработана методика сорбционноспектрофотометрического определения гистидина и триптофана в водных растворах. Через стеклянную колонку, заполненную $3.0000 \pm 0.0002$ г сополимера (высота слоя $15.00 \pm 0.01 \mathrm{~cm})$ на основе 1-винил-3,5-диметилпиразола и ЭГДМА с соотношением $\Phi \mathrm{M:CA}=1: 15$ со скоростью $5 \mathrm{~cm}^{3} /$ мин пропускают предварительно отфильтрованную и подкисленную раствором $\mathrm{HCl}$ до $\mathrm{pH}$ 2-2.5 пробу водного раствора аминокислоты объемом $250 \mathrm{~cm}^{3}$. После этого колонку промывают $50 \mathrm{~cm}^{3}$ раствора $0.1 \mathrm{M} \mathrm{NaOH}$. Спектрофотометрически (Shimadzu $U V-1800,211$ нм для гистидина и 279 нм для триптофана) определяют концентрацию аминокислоты в элюате.

Правильность методики проверяли методом «введено-найдено» в водных растворах (табл. 4). Предел обнаружения, рассчитанный по 3-s критерию, при объеме пробы $250 \mathrm{~cm}^{3}$ составляет $6 \cdot 10^{-6}$ моль. По чувствительности и экспрессности разработанный способ превосходит химические методы определения аминокислот в водных растворах, представленные в Государственной Фармакопеи [25].

Таблица $4 *$. Результаты сорбционно-спектрофотометрического определения аминокислот в препаратах $(n=5, P=0.95)$

\begin{tabular}{|c|c|c|c|c|}
\hline Объект анализа & Определяемый компонент & $\begin{array}{c}\text { Введено, } \\
\text { ммоль }\end{array}$ & $\begin{array}{c}\text { Найдено, } \\
\text { ммоль }\end{array}$ & $S_{r}$ \\
\hline $\begin{array}{c}\text { Сточные воды пищевого } \\
\text { производства }\end{array}$ & Гистидин & 1.30 & $1.23 \pm 0.05$ & 0.02 \\
\cline { 2 - 5 } & Триптофан & 2.45 & $2.41 \pm 0.05$ & 0.02 \\
\hline
\end{tabular}

*Примечание. В образце без добавок аминокислоты не обнаружены. 


\section{Заключение}

Таким образом, установлено, что сорбционное концентрирования гистидина и триптофана наиболее эффективно проводить в кислой среде с использованием сорбента ВДМП-ЭГДМА=1:15, синтезированного в хлороформе. Десорбция проводится $0.1 \mathrm{M}$ водным раствором $\mathrm{NaOH}$. Данный образец характеризуется малыми значениями времен сорбции-десорбции, а также высокими значениями коэффициентов концентрирования и степени концентрирования по сравнению с другими, что будет положительно сказываться на аналитических характеристиках процесса концентрирования. На основании проведенных исследований разработана методика сорбционноспектрофотометрического определения гистидина и триптофана в водных растворах.

\section{Список литературы}

1. Филиппов О.А., Тихомирова Т.И., Цизин Г.И., Золотов Ю.А. // Журн. аналит. химии. 2003. Т. 58. № 5. С. 454-479.

2. Золотов Ю.А., Цизин Г.И., Моросанова Е.И., Дмитриенко С.Г. // Успехи химии. 2005. Т. 74. № 1. С. 41-66.

3. Архипова А. А., Статкус М. А., Цизин Г.И., Золотов Ю.А. // Журн. аналит. химии. 2015. T. 70. № 12. C. 1235-1253.

4. Castro R., Natera R., Durán E., GarcíaBarroso C.// Eur. Food. Res. Technol. 2008. Vol. 228. No 1. pp.1-18. doi:10.1007/s00217008-0900-4

5. Ferreira-Caliman M.J., Turatti I. C.C., Lopes N.P., Zucchi R et al. // J. Chem. Ecol. 2012. Vol. 38. No 4. pp. 418-426. doi:10.1007/s10886-012-0109-7

6. Wang J., Li A., Xua L., Zhou Ya.// Chin. J. Polym. Sci. 2010. Vol. 28. No 2. pp. 231-239. doi:10.1007/s10118-010-9003-3

7. Shan J., Wang L., Yu H., Tai Y. et al.// J. Zhejiang Univ-Sci A (Appl Phys \& Eng). 2015. Vol. 16. No 8. 1 pp. 669-679. doi:10.1631/jzus.A1500096

8. Keshavarz A., Zilouei H., Abdolmaleki A., Asadinezhad A., Nikkhah A.A. // Int. J. Environ. Sci. Technol. 2016. Vol. 13. pp. 699-710. doi:10.1007/s13762-015-0908-9

9. Karadag K., Sonmez H. B. // J. Polym. Res. 2013. Vol. 20. No 3. pp.305-313. doi:10.1007/s10965-013-0305-3

10. Kizil S., Sonmez H. B. // J. Polym. Res. 2016. Vol. 23. No 1. pp.55-65. doi:10.1007/s10965-016-0938-0

11. Дмитриенко С.Г., Ирха В.В., Кузнецова А.Ю., Золотов Ю.А. // Журн. аналит. химии. 2004. Т. 59. № 9. С. 902-911.
12. Дмитриенко С.Г., Попов С.А., Чумичкина Ю.А., Золотов Ю.А. // Журн. физ. химии. 2011. Т. 85. № 3. С. 542-547.

13. Мокшина Н.Я. Экстракция аминокислот и витаминов. Воронеж: Воронеж. гос. технол. акад. 2007. $246 \mathrm{c.}$

14. Кушнир А. А., Суханов П.Т., Чурилина Е.В., Шаталов Г.В. // Журн. прикл. химии. 2014. T. 87. № 5. С. 589-589.

15. Чурилина Е.В., Кушнир А.А., Суханов П. Т., Шаталов Г.В. // Журн. аналит. химии. 2015. T. 70.№ 2.C. 138-142.

16. Ермак С.С., Шаталов Г.В. / Тез. докл. Полимеры-2010 V Международная Каргинская конференция, Москва, 21-25 июня 2010 г. : С. 40 .

17. Анненков В.В. Дис. док. хим. наук. Иркутск. 2001.319 с.

18. Кирш Ю.Э. Поли-N-винилпирролидон и другие поли-N-виниламиды. М. Наука. 1998. $252 \mathrm{c}$.

19. Якубке Х.Д., Ешкайт Х. Аминокислоты, пептиды, белки. Пер. с нем. М. Мир. $1985.456 \mathrm{c}$.

20. Шкинев В.М., Мокшина Н.Я., Хохлов В.Ю., Спиваков Б.Я. // Докл. акад. Наук. 2013. T. 448. № 4. C. 1-3.

21. Мокшина Н.Я., Быковский Д.В., Шаталов Г.В., Пахомова О.А. // Журн. аналит. химии. 2016. Т. 71. № 2. С. 208-211.

22. Кузнецов В. А. Дисс. док. хим. наук. M. 2007. 361 c.

23. Москвин Л.Н., Родинков О.В. Методы разделения и концентрирования в аналитической химии. М. «Интеллект». 2010. 391 с.

24. Шаталов Г.В., Вережников В.Н., Плаксицкая Т.В., Кузнецов В.А. и др.// Высокомолек. соед. А. 2006. Т. 48. № 6. С. 892-898. 
25. Государственная фармакопея Российской Федерации / М-во здравоохранения и социал. развития Рос. Федерации и др . М. :
Науч. центр экспертизы средств мед. применения, 2010 .Ч. 2 .12-е изд. 2010. 480 с.

\section{References}

1. Filippov O. A., Tikhomirova T.I., Tsizin G.I., Zolotov Yu.A., J. Analyt. Chem, 2003, Vol. 58, No 5, pp. 398-423. doi:10.1023/A:1024061610788

2. Zolotov Yu.A., Tsizin G.I., Morosanova E.I., Dmitrienko S.G., Rus. Chem. Rev., 2005, Vol. 74, No 1, pp. 37-60. doi:10.1070/RC2005v074n01ABEH000845

3. Arkhipova A.A., Statkus M.A., Tsizin G.I., Zolotov Yu.A., J. Analyt. Chem, 2015, Vol. 70, No 12, pp. 1413-1431. doi:10.1134/S1061934815120047

4. Castro R., Natera R., Durán E., GarcíaBarroso C., Eur. Food. Res. Technol, 2008, Vol. 228, No 1, pp.1-18. doi:10.1007/s00217-0080900-4

5. Ferreira-Caliman M.J., Turatti I. C.C., Lopes N.P., Zucchi R. et al., J. Chem. Ecol, 2012, Vol. 38, No 4, pp. 418-426. doi:10.1007/s10886-012-0109-7

6. Wang J., Li A., Xua L., Zhou Ya., Chin. J. Polym. Sci, 2010, Vol. 28, No 2. pp. 231-239. doi:10.1007/s10118-010-9003-3

7. Shan J., Wang L., Yu H., Tai Y. et al., J. Zhejiang Univ-Sci A (Appl Phys \& Eng), 2015, Vol. 16, No 8, pp. 669-679. doi:10.1631/jzus.A1500096

8. Keshavarz A., Zilouei H., Abdolmaleki A., Asadinezhad A. et al., Int. J. Environ. Sci. Technol, 2016, Vol. 13, pp. 699-710. doi:10.1007/s13762-015-0908-9

9. Karadag K., Sonmez H.B., J. Polym. Res, 2013, Vol. 20, No 3, pp.305-313. doi:10.1007/s10965-013-0305-3

10. Kizil S., Sonmez H.B., J. Polym. Res, 2016, Vol. 23, No 1, pp.55-65. doi:10.1007/s10965-016-0938-0

11. Dmitrienko S.G., Irkha V.V., Kuznetsova A.Yu., Zolotov Yu.A., J. Analyt. Chem., 2004, Vol. 59, No 9, pp. 808-817. 10.1023/B:JANC.0000040694.23348.45

12. Dmitrienko S.G., Popov S.A., Chumichkina Yu A., Zolotov Yu.A., Rus. J. Phys. Chem. A, 2011, Vol. 85, No 3, pp. 472477. doi:10.1134/S0036024411020087

13. Mokshina N.Ya. Ekstractsia aminokislot i vitaminov, Voronezh, Voronezh gos, teknol. akad. Publ,. 2007, 246 p.

14. Kushnir A.A., Sukhanov P.T., Churilina E.V., Shatalov G.V., Rus. J. App. Chem., 2014, Vol. 87, No 5, pp. 579-584. doi:10.1134/S1070427214050073

15. Churilina E. V., Kushnir A.A., Sukhanov P.T., Shatalov G.V., J. Analyt. Chem., 2015, Vol. 70, No 2, pp. 130-135. doi:10.1134/S1061934815020021

16. Ermak S.S., Shatalov G.V., Polymers2010: Proceedings of the V International Kargin Conference, June 21-25, 2010, Moscow, pp.40.

17. Annenkov V. V. Dis. dok. khim. nauk. Irkutsk, 2011, $319 \mathrm{p}$.

18. Kirsh Yu.E. Water Soluble Poly-NVinylamides: Synthesis and Physicochemical Properties. London: Methuen \& Co. Ltd, New York: John Wiley \& Sons, Inc., 1998, 240 p.

19. Von H.-D. Jakubke, H. Jeschkeit. Aminosäuren, Peptide, Proteine..Verlag Chemie, Weinheim Deerfield Beach/Florida, Basel 1982, 505 p. doi: 10.1002/nadc. 19820301112

20. Shkinev V.M., Mokshina N.Ya., Khokhlov V.Yu., Spivakov B.Ya., Doklady Khimii, 2013, Vol. 448, Part 2, pp. 49-51. doi:10.1134/D1061935615020045

21. Mokshina N.Ya., Bykovskii D.V., Shatalov G.V., Pakhomova O.A., J Analyt Chem, 2016, Vol. 71, No 2, p. 201-204. doi: 10.1134/S1061934816020106

22. Kuznetsov V. A. Diss. doc. khim. nauk. M., 2007, 361 p.

23. Moskvin L.N., Rodnikov O.V. Metody razdeleniya $\mathrm{i}$ koncentririvaniya $\mathrm{v}$ analiticheskoi khimii. M., «Intellekt», 2010, 391 p.

24. Shatalov G.V., Verezhnikov V.N., Plaksitskaya T.V., Kuznetsov V.A. et al., Polymer Science. Ser. A., 2006, Vol. 48, No 6, pp. 563568. doi:10.1134/S0965545X06060022

25. Gosudarstvennaya Farmokopeya Rossiiskoi Federacii / Ministerstvo zdravokhraneniya i social'nogo razvitiya Rossiiskoi Federacii i dr., 2010, Part 2. M., 480 p. 
Лавлинская Мария Сергеевна - аспирант кафедры химии высокомолекулярных соединений и коллоидов Воронежского государственного университета, Воронеж; +7(950)7585216

Кузнецов Вячеслав Алексеевич - д.х.н., доцент, профессор кафедры химии высокомолекулярных соединений и коллоидов Воронежского государственного университета, Воронеж; +7(920)4523733

Хохлов Владимир Юрьевич - Д.Х.н., доцент, профессор кафедры аналитической химии Воронежского государственного университета, Воронеж; +7(915)5485515

Шаталов Геннадий Валентинович - д.Х.н., профессор, профессор кафедры химии высокомолекулярных соединений и коллоидов Воронежского государственного университета, Воронеж; телефон +7(908)1307171
Lavlinskaya Maria S. - post-graduate student of chair of macromolecules compounds and colloid of Voronezh State University, Voronezh; e-mail: maria.lavlinskaya@gmail.com

Kuznetsov Vyacheslav A. - Dr. Sci. (Chem.), professor of chair of macromolecules compounds and colloid of Voronezh State University, Voronezh; e-mail: dr.v.kuznetsov@gmail.com

Khoklov Vladimir Yu. - Dr. Sci. (Chem.), professor of chair of analytical chemistry of Voronezh State University, Voronezh, e-mail: khokhlov@chem.vsu.ru

Shatalov Gennadii V. - Dr. Sci. (Chem.), professor of chair of macromolecules compounds and colloid of Voronezh State University, Voronezh; email:vms159@mail.ru 